\title{
Promise, premise, and reality: the case of voluntary environmental non-migration despite climate risks in coastal Bangladesh
}

\author{
Md. Nasif Ahsan ${ }^{1}$ D $\cdot$ Fatema Khatun ${ }^{1}$ D $\cdot$ Pankaj Kumar $^{2}$ (D) Rajarshi Dasgupta $^{2}$ (D) Brian Alan Johnson ${ }^{2}$ (D) \\ Rajib Shaw ${ }^{3}$ (D)
}

Received: 7 December 2020 / Accepted: 21 November 2021 / Published online: 11 December 2021

(c) The Author(s) 2021

\begin{abstract}
Despite confronting severe climatic risks, many people prefer to remain in climate hazard-prone areas rather than migrate. Environmental non-migration behavior, however, has gained relatively little research attention in the field of migration processes. This study aims to unveil the determinants motivating voluntary environmental non-migration decisions in coastal Bangladesh, an area highly exposed to flooding and other climate-related hazards (e.g., soil salinization). Applying a systematic random sampling, we selected 556 household respondents for a questionnaire survey from 14 villages of two coastal districts: Khulna and Satkhira. Applying a mixed method (i.e., both quantitative and qualitative) approach, major empirical results of this study suggest that even though all respondents lived in a similar situation in terms of climatic hazard and exposure, $88 \%$ of the respondents reported themselves as voluntary non-migrants. Furthermore, these non-migrants enjoyed higher socioeconomic and sociopsychological advantages and availed more local support from different government and non-government organizations than involuntary non-migrants. Again, mutual assistance, connection with social groups, natural resource access, sense of secured livelihood, stable societal atmosphere, and participation in decision-making in society appeared to build their higher degree of social capital $\left(\chi^{2}(4)=57.80 ; p<0.000\right)$ compared to involuntary non-migrants. All these features lead to a favorable environment that ultimately drove the respondents to become voluntary non-migrants.
\end{abstract}

Keywords Voluntary non-migration $\cdot$ Climatic shock $\cdot$ Climatic risk $\cdot$ Social capital $\cdot$ Bangladesh

\section{Introduction}

Extreme weather events (e.g., droughts, cyclones, and floods), many of which are thought to be exacerbated by climate change, affect the livelihoods and safety of people

Communicated by Bishawjit Mallick and accepted by Topical Collection Chief Editor Christopher Reyer

This article is part of the Topical Collection on Environmental Non-Migration: Frameworks, Methods, and Cases

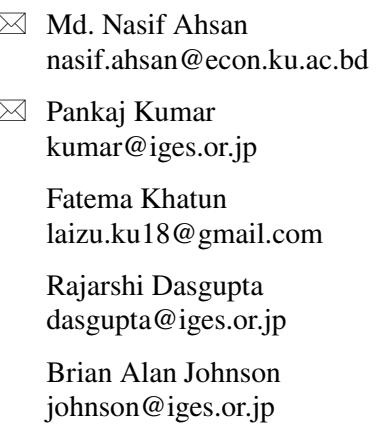

at risk (Adger et al. 2014). In recent years, extreme climatic events displaced approximately 24.9 million people globally, with approximately 9.5 million people displaced in South Asia alone (IDMC 2020). By 2050, one in 45 people is expected to be displaced globally due to climate change impacts (Comprehensive Disaster Management ProgrammeII 2014).

To cope with climate risks, migration is often chosen as an adaptation option (Jha et al. 2018). Migration is a driving force of economic growth and is associated with

\section{Rajib Shaw}

shaw@sfc.keio.ac.jp

1 Economics Discipline, Social Science School, Khulna University-9208, Khulna, Bangladesh

2 Natural Resources and Ecosystem Services, Institute for Global Environmental Strategies (IGES), Hayama, Kanagawa 240-0115, Japan

3 Graduate School of Media and Governance, Shonan Fujisawa Campus, Keio University, Fujisawa, Japan 
environmental hazards as a demographic process (Hunter 2005). Over the last several decades, (environmental) migration has become more common in climate hazardprone developing countries (Petrova 2021; Zander and Garnett 2020; Van Heelsum 2016). In the case of climatic shocks, income inequality and disparity in living standards tend to be the dominant factors of environmental migration from rural to urban areas (Jha et al. 2018). The decision to migrate is based on a rational decision-making process, which involves weighing the potential costs and benefits of migrating (Mallick and Schanze 2020). This decision is also affected by individuals' or households' aspirations and capacity to cope with the climatic shocks (Schewel 2020). In households, the migration decision is generally made via a consensus among the household members, by assessing the trade-offs between income prospects in the new location and consumption smoothing ${ }^{1}$ at the origin point (considering, e.g., impacts of climatic shocks) (Jha et al. 2018).

On the contrary, environmental non-migration is often considered as a contingency when migration is not feasible (Mallick and Schanze 2020). Factors affecting non-migration decisions are relatively less studied in the disaster risk reduction/climate change adaptation research domain (Zickgraf 2019). Social researchers draw upon various migration theories based on social and economic realities, excluding non-migration behavior (Schewel 2020). As a result, migration theory is methodologically well developed, while non-migration behavior has yet to be systemically framed. Recently, environmental non-migration theory is becoming an emerging issue in the premise of climate-induced displacement, as it sometimes occurs for voluntary reasons, while other times for involuntary reasons (i.e., when people are trapped in their current location).

The government of the UK first discussed the idea of "trapped population" in its report on Migration and Global Environmental Change in 2011 (The UK Government Office for Science 2011). The trapped population (also called involuntary non-migrants) are those individuals having the aspiration to move but not possessing sufficient resources (predominantly financial resources) to do so. Climatic risks may provoke people with higher aspirations to leave their original living place, while these risks may also adversely affect their capacity to move. For instance, in the case that an extreme weather event destroys at-risk peoples' houses, the adverse situation may propagate their aspiration to move while simultaneously reducing their capacity to move (e.g., by reducing/losing agricultural yields, and thereby creating financial constraints to moving). To handle such climatic

\footnotetext{
${ }^{1}$ Refers to the attempts of optimizing our living standards by maintaining a proper balance between spending and saving during our lifetime.
}

risks, socioeconomic and sociopolitical progress are treated as the influencing features to enhance an individual's resilience capacity (Ayeb-Karlsson et al. 2018). Again, Zickgraf (2019) demonstrated that rural people in developing countries are often trapped in the aftermath of extreme climatic events because of economic constraints, which implies their limited capacity. That said, not all non-migrants are trapped; some are voluntary non-migrants even though they are at risk. People may voluntarily choose not to move to other places because of their established social network and/or cultural commonality (Shamsuddoha et al. 2011), among other reasons. For instance, despite being exposed to adverse climate change impacts, people persisted in their locality in the Rimac river valley of Peru because of non-economic benefits rather than resource constraints (Adams 2016). Ayeb-Karlsson et al. (2020) explored the role of psychosocial factors on people's non-migration decision considering their well-being status. Zickgraf (2019) argued that political determinants are also responsible for shaping the non-migration decision, while in some cases people do not intend to migrate because of their place attachment (AyebKarlsson et al. 2018). From this perspective, the decision to unintentionally stay in a climate hazard-prone area (i.e., involuntary non-migrant) is not always permanent, as the local households or communities may become voluntary non-migrants if they become more resilient to the adverse effects of climatic shocks over time (Mallick and Sultana 2017).

Over the last few decades, migration has attracted more attention than non-migration in social research. From the empirical perspective, motivation for migration is a longstanding reality (Carling and Collins 2018) together with a dynamic and complex process that is unevenly distributed in the low-income countries (Hjälm 2014). Though migration is often attributed as a successful adaption measure to cope with climatic shocks, it creates a long debate within the discourse of decision-making for climatic risk scenarios (Ayeb-Karlsson et al. 2018). Ayeb-Karlsson et al. (2020) opined that theories of migration are often inclined with "mobility bias" focusing particularly on the drivers and flows of migration by significantly bypassing the nonmigration (i.e., immobility) issues and outcomes. In this regard, expressing the importance of centripetal forces along with centrifugal ones, Schewel (2020) and Bal and Willems (2014), respectively, suggested that conventional migration theories overlook the pattern of non-migration, as those theories cannot explain why certain people are not willing to migrate despite encountering covariate shocks from extreme climatic events in their localities. To date, only a handful of migration-related studies have attempted to frame the non-migration behavior. Therefore, this less discussed non-migration issue needs more attention, as the exploration of opportunities and potential benefits of 
staying in one's locality is a time-demanding issue. In this regard, it is essential to investigate empirically how different factors influence an individual's or a household's voluntary non-migration behavior. Therefore, this study explores the responses of climate shock-affected people in Southwestern coastal Bangladesh toward non-migration behavior by investigating factors that motivate their voluntary non-migration decision through a case study approach. Throughout the rest of this paper, we denote voluntary environmental non-migration as "voluntary non-migration."

\section{Conceptual considerations}

People at risk try to adopt various strategies to cope with climatic shocks and stresses. Migration is a notable adaptation strategy to cope with risks (including climate risks) and help them diversify their livelihood options (Mallick and Schanze 2020). However, Biswas and Mallick (2020) also suggested that migration is not necessarily compulsory for all affected people. When people have sufficient capital to diversify their livelihood strategies and ensure their well-being even in the face of climatic risks, they may opt to stay at their concerned localities. Hence, the migration/non-migration decision process is a dynamic and complex phenomenon, shaped by, e.g., environmental, demographic, social, economic, and political factors, as well as availability and access to natural resources (Olsson et al. 2014; Bhusal and Kimengsi 2019; Tebboth et al. 2019; Mallick and Schanze 2020; Biswas and Mallick 2020; Ayeb-Karlsson et al. 2019; Fischer et al. 2000; Schewel 2020).

The sociodemographic aspects of an individual or household (such as age, gender, household size and structure, education and training facilities, asset holdings, and place attachment) have an impact on migration/non-migration decisions. For example, female household members are often less likely to migrate than male members due to childcare/family care responsibilities, and greater insecurity and sexual harassment in new destinations (Mallick 2019). Younger people are more likely to move from their localities because of better education and employment opportunities (Bhusal and Kimengsi 2019), whereas older adults are more likely to prefer staying in their current localities mainly due to place attachment. Again, these sociodemographic factors significantly influence social premises such as access to basic needs, decision-making power, and social network, which affect their migration/non-migration decision. Vulnerable people are more likely to receive social support from communities that help overcome difficulties, especially in post-disaster times (Bhusal and Kimengsi 2019). Furthermore, educated and affluent people who are honored and respected by society enjoy their roles in decision-making in society (Mallick 2019), and thus, they are less likely to migrate. Social network reduces the cost of migration by providing housing and settlement facilities in the destination and increasing propensity to migrate (Hunter et al. 2015), while economic factors (i.e., diversity of livelihoods, innovations, better income prospects) positively affect people's migration decisions (Mallick et al. 2020). In addition, benefits from utilizing local natural resources make people resilient to adverse situations and increase their adaptive capacity to stay in hazard-prone places (Mallick 2019). However, sometimes local political leaders control people's access to available natural resources (Hunter et al. 2015).

Considering the theoretical discourses mentioned above, in this study, we developed and applied a customized framework adapted from Vigil et al. (2019) to present the interconnection among diverse factors affecting migration/non-migration decision. We name this framework as the Paradigm of Migration Decision, presented by Fig. 1, where each box/ circle with a number on its upper right corner exhibits specific dimension.

\section{Research method}

This section describes methodological steps applied in this study, including the study locations, the procedure for sample selection, data collection, and the analytical approach for analyzing the data.

\section{Study area}

We took two criteria into consideration for selecting study locations in Bangladesh. First, the area must be located in a hydrometeorological hazard-prone coastal region; and second, the transport network should be underprivileged in terms of (re)construction, repairing, and budget allocation. Following the criteria, we selected villages from five unions ${ }^{2}$ of Khulna and Satkhira districts as study locations, as presented in Fig. 2. Over the last one and half decades, these study locations were battered by tropical cyclones ranging from category-2 to category-5 (EMDAT 2020). Among the most devastating recent cyclones were Amphan (in 2020), Fani (in 2019), Mora (in 2017), Roanu (in 2016), Mahashen (in 2013), Aila (in 2009), and Sidr (in 2007) (Ahsan and Khatun 2020; Ahsan et al. 2020).

\footnotetext{
${ }^{2}$ Unions are the smallest rural administrative and local government units in Bangladesh.
} 


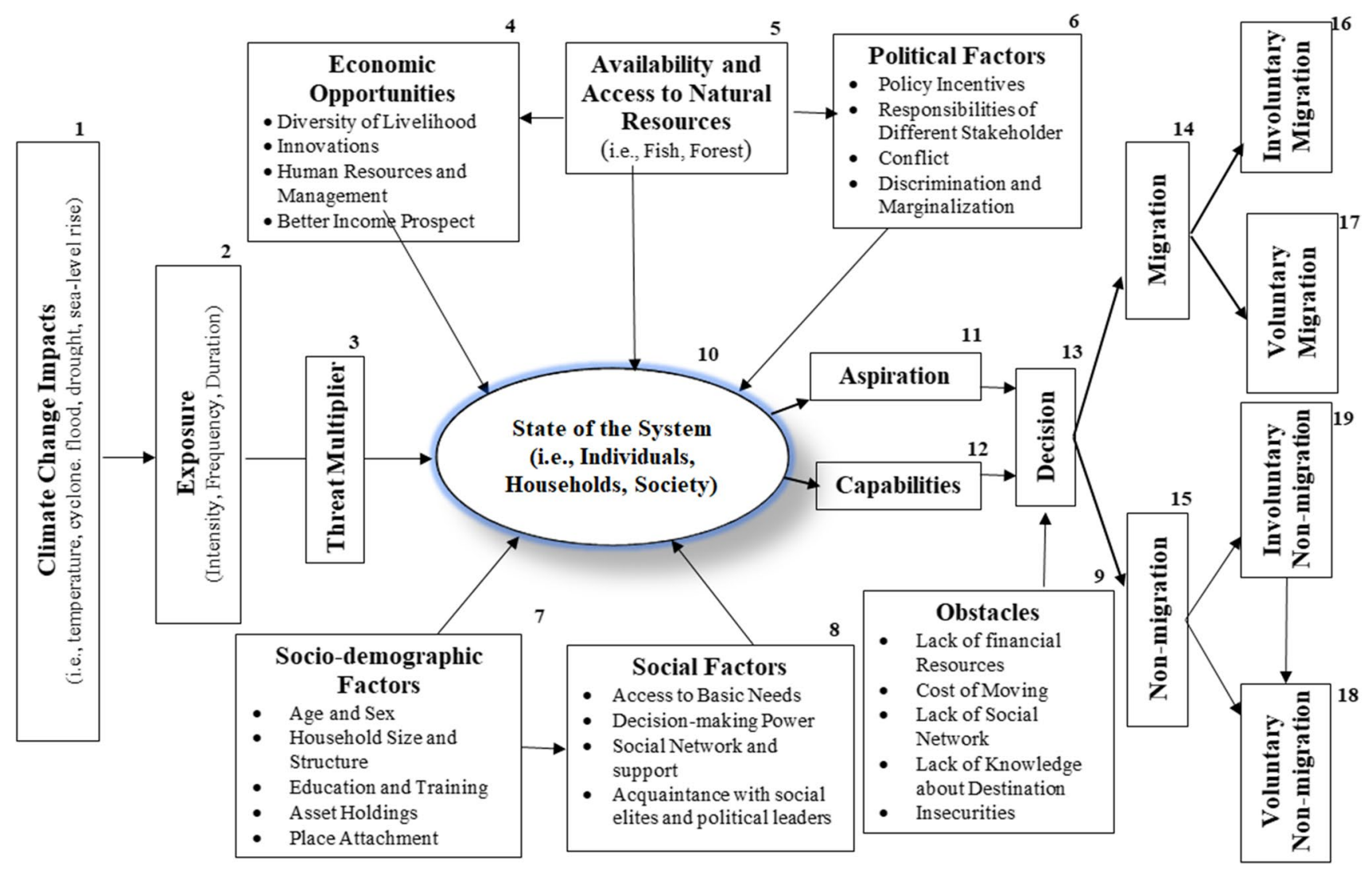

Fig. 1 Major determinants of voluntary environmental non-migration decision

Fig. 2 Geographical location points of study areas (HDX 2020)

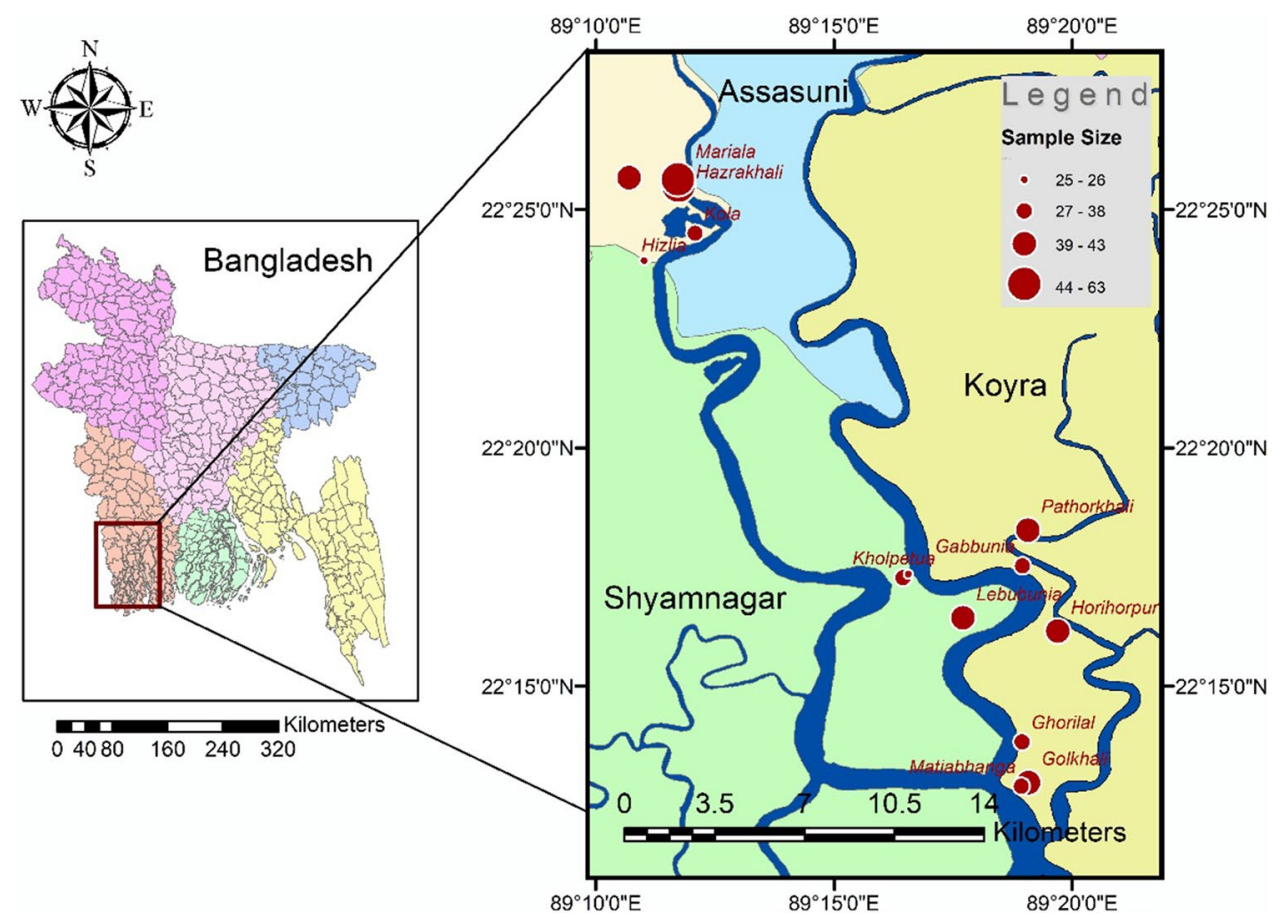




\section{Data collection procedure and sampling method}

We used primary data for the analyses conducted in this study. For collecting primary data, we performed a faceto-face household-level survey using a structured questionnaire. The questionnaire was composed into five sections: the first section dealt with the questions on respondents' personal information (i.e., mainly socioeconomic and sociodemographic information); the second section covered hazard- and damage-related information; the third section dealt with social attribute-related information; the fourth section addressed migration-related questions, and the final section covered respondents' access to natural resources-related information. After reviewing the relevant literature, discussing with two experienced Cyclone Preparedness Program (CPP) volunteers, and performing five Focus Group Discussions (FGDs) with participants from different walks of life, the questions for the draft questionnaire were finalized. A piloting was performed with 25 respondents in June 2020 using this draft questionnaire, and necessary modifications were addressed in the final version of the questionnaire. We incorporated a total of 68 questions in the final version of the questionnaire.

We applied a multi-stage sampling approach to select the survey respondents. In this regard, at the first stage, we purposively chose two districts - Khulna and Satkhira based on the conditions mentioned in the "Study area" sub-section. In the second stage, we purposively selected five unions that suffered most due to hydrometeorological hazards over the last decade from the aforesaid two districts. At the third stage, we randomly selected 14 villages from five unions applying a lottery method.

Our study locations were hit by a category- 5 tropical cyclone (Amphan) in May 2020 followed by river embankment breaches, which inundated nearly $83 \%$ of all villages in our study locations. As a result of this inundation, many households from these villages moved toward the dry areas together with the unaffected segments of the embankment. Under the circumstances, a random selection of sample respondents based on an electoral list from the local government administration office was not possible to apply. Therefore, we adopted a systematic random sampling for selecting sample households. Specifically, we performed a second lottery by blindly drawing a piece of paper with one of five numbers on it $(7,12,17,22$, or 27$)$, where the number written corresponded to the proportion of households to be sampled. In this lottery, a paper with the number " 12 " was drawn. Based on this lottery result, for the survey sampling, we selected every twelfth household on the river embankment in the case of inundated villages, while in the case of non-inundated villages, we chose every twelfth household from both sides of the main connecting road from the central business point to inside the village (odd attempts on left side and even attempts on right side). Based on the condition mentioned in the following sub-section, in total, our sample consisted of a total of 556 household respondents from 14 villages in five unions, as shown in Fig. 2.

\section{Analytical approach}

As it is difficult to set a definitional paradigm of "migration/ non-migration," especially for climate-sensitive regions (due to their complex characteristics), we framed and applied a simple definition of non-migration in this study. Thus, in line with our study design, we considered a respondent as a voluntary non-migrant if he/she (despite climatic extreme events) along with all members of the concern household (including its head if the respondent is not household head) willingly stayed in the same and/or adjacent locality for at least two decades. In this case, the aforesaid time span is considered as 2000 to 2020 , during which seven tropical cyclones battered our study locations (see Table C in Appendix). We deployed a mixed method as an analytical approach in this study, where we applied quantitative tools mostly. We considered relevant statements by household respondents during face-to-face survey and FGD participants for qualitative analysis. For quantitative analysis, we used linear correlation, parametric, and non-parametric testing tools. In this regard, we divided the quantitative analysis plan into three segments.

First, we differentiated between two groups of samples: voluntary non-migrants and involuntary non-migrants (i.e., those who willingly did not migrate and those who unwillingly did not migrate). Then, we applied relevant parametric and non-parametric tests (correlation, $z$-test, chi-squared test) to analyze differences between the two said groups together with the association among relevant covariates.

Secondly, we deployed a principal component analysis (PCA) to extract major dimensions (composed of clusters of variables) of the respondents' non-migration decision. We chose to apply PCA as it is a statistical tool for data reduction and can be used to re-express multivariate data with fewer dimensions (i.e., components). In other words, by applying PCA, one can mathematically derive a relatively small number of variables expressed in clusters to convey as much of the information in the observed variables as possible (Field 2013). By applying PCA, we re-oriented the data in such a way that a multitude of original variables was summarized with relatively few "factors" or "components" that captured the maximum possible information (variation) from a large chunk of original variables.

Finally, having figured out the major components using PCA, we applied a binary logistic regression model, presented in Eq. 1, where the dependent variable $(p)$ takes a value of 1 if the respondent is a voluntary non-migrant only and 0 if otherwise. This "otherwise" included the 
respondents whose replies were both "no" and "not sure" to the question if they willingly did not move to other areas. We performed this regression analysis to determine the driving factors behind the non-migration decision of the respondents. In this regression model, we incorporated the predicted values of PCA components $\left(P_{k}\right)$, socioeconomic and sociodemographic characteristics $\left(Z_{k}\right)$, and other relevant issues $\left(S_{k}\right)$ as independent variables. In Eq. 1, subscript $k$ denotes respondents, $\beta$ is a constant term, parameters $\gamma, \delta$, and $\varphi$ are to be estimated, and $\varepsilon$ is an idiosyncratic error term. All the statistical tests in this study were performed by using a statistical package known as SPSS (version 22). Table A in the Appendix exhibits the list of variables used in this study including their definition, measuring unit, and adapted sources.

$\operatorname{Ln}\left(\frac{p}{1-p}\right)_{k}=\beta_{k}+\gamma P_{k}+\delta Z_{k}+\varphi S_{k}+\varepsilon_{k} \ldots \ldots \ldots$

To make contrasts with the results from PCA and logistic regression, we used relevant statements by household respondents during face-to-face survey and FGD participants.

\section{Results}

\section{Socioeconomic profile of sampled respondents}

Table B in the Appendix presents the socioeconomic profile of the respondents of this study. The male-female ratio of the respondents was 1.18 where nearly $75 \%$ of male respondents were household heads implying a male-dominant society. The average age of the respondents was $43( \pm 13.36)^{3}$ years implying that most of the respondents were at their middle age. The average household size was $4.75( \pm 2.33)$ members, which is slightly higher than that of the national average (4.06 members) (BBS 2016). Ninety-two percent of respondents reported themselves as married. The literacy level of the respondents was very low, with nearly $26 \%$ respondents never having gone to school and only $22 \%$ of respondents having completed primary level education. The mean schooling years were $5.1( \pm 4.23)$ years for sampled respondents. The average number of earning member(s) per household was $1.32( \pm 0.64)$ persons denoting a significantly high dependency ratio within households. Slightly over $94 \%$ of respondents were involved in diverse occupations, of whom nearly $48 \%$ reported themselves as contract laborers, $15 \%$ reported themselves to be directly engaged with shrimp farming and trading, and $4.5 \%$ were self-employed.

\footnotetext{
3 Values with " \pm " sign denote the standard deviation for the sample.
}

However, a large proportion of the respondents $(72 \%)$ had no regular monthly income. The standard deviation of their reported monthly income was twice as much as the average monthly income, implying a substantially uneven income distribution. In contrast, considering the Cost of Basic Needs ${ }^{4}$ (expenditure) [BCN], $40.65 \%$ of respondents were found to be living below the poverty threshold level. Most of the respondents (70\%) were living in weakly built houses (i.e., kancha houses), while just over $10 \%$ of respondents reported to live in temporary settlements on river embankments. All of the respondents were living less than a kilometer from eroded rivers, implying exposure to disaster risk, while nearly $88 \%$ of respondents reported as living near to river embankment. Nearly $42 \%$ respondents reported having lost their land due to river-bank erosion over the past decades. Respondents reported having been living in the same region, on average, for around 42 years and 2.5 generations.

A large number $(91.7 \%)$ of the respondents had no food storage facilities. In the case of irregular household income sources, around $50.7 \%$ of the respondents had poultry, $33.2 \%$ had cattle or livestock, and $25.5 \%$ had kitchen gardens. $24.28 \%$ of the sample households had no access to electricity. Only $18 \%$ of them always used sanitary latrine, and more than $50 \%$ had no access to drainage and solid waste management facilities. However, almost $87.8 \%$ of the respondents reported that there was an embankment along the river near their current living place. Nonetheless, almost $41.7 \%$ of the respondents reported that on average, they lost their land at least once with a standard deviation of 1.38 due to river erosion.

\section{Hazard damage scenario in study locations}

Over the last 50 years, Bangladesh has experienced nearly $40 \%$ of the global tropical cyclones, and nearly $85 \%$ of global cyclone-related economic and non-economic damages occurred along the Bangladesh coast (Ahsan et al. 2016; Biswas et al. 2018). Among the previous ones, cyclone 04B (1988), cyclone Gorky (1991), Sidr (2007), Aila (2009), cyclone Bulbul (2019), and cyclone Amphan (2020) caused great damages in terms of mortality rate and economic loss in Southwestern coastal Bangladesh, including our study locations, as presented in the Table $\mathrm{C}$ in Appendix. Within 6 months (November, 2019-May, 2020), two consecutive cyclones - cyclone Bulbul and cyclone Amphan - made local people's life very challenging as the latter one ravaged nearly $150-\mathrm{km}$ river embankment with at least 84 cracks in several places that might eventually create significant

\footnotetext{
${ }^{4}$ Bangladesh Bureau of Statistics calculates BCN as a poverty threshold value, which is US\$244.2/capita/year at adjusted value for year 2018 .
} 
havoc in our study locations (UNB 2020). A recent study by Kumar et al. (2020) suggests that the adaptive capacity of people in one of our study locations was adversely affected by recent hydro-meteorological hazards, especially cyclones. Respondents of this study reported living within less than half a kilometer from the river implying they were living in highly exposed areas and just over $45 \%$ of them thought that the river embankments were not able to protect them. Nearly $79 \%$ of respondents had encountered river bank erosion led displacement and they lost their land, on average once, due to the said erosion in their lifetime. Over the last several decades, a common incident in the aftermath of any moderate to strong cyclone was river embankment breach led inundation. Respondents reported that they suffered inundation on an average of 35 days in a year. Aside from tropical cyclone and inundation, about $73 \%$ of respondents reported to encounter salinity intrusion problem, which significantly affected their agriculture-based livelihood. Furthermore, respondents appeared to perceive a significant adverse impact of future climatic extreme events on their degree of access to local natural resources for livelihood $\left(\chi^{2}(16)=310.38 ; p<0.000\right)$. Our sampled respondents, on an average, incurred BDT 74,261 (US\$ 874.69) over the last 5 years due to hazard-induced damages. In this regard, the following statement from a male respondent from Ghorial village would help us to apprehend the scenario.

"There is hardly any person in this area who does not incur any loss due to hazards. I have been living in this area for the last 64 years and I have experienced several deadly cyclonic hazards that battered our area. I worked as a contract labor in different shrimp production units (known as Gher), but during cyclone Sidr, while evacuating to cyclone shelter at the very last moment I suffered a physical injury, and my left hand became paralyzed. Since then, I cannot work as a laborer. I borrowed money from others and started a small grocery shop in the local market. I think these natural hazards, especially cyclones, are quite common phenomena in our life that we cannot skip. So, I accept these hazard events as a usual part of my life. I believe people in my locality also think like myself on this hazard issue."

\section{Non-migration decision among people at risk: voluntary vs. involuntary}

Respondents were asked if they willingly decided to stay at their current places even after being encountered significant economic (e.g., land-loss) and non-economic (e.g., the demise of household member(s)) damages over at least the last 20 years. Just over $88 \%$ of the respondents replied affirmatively, of whom nearly $11 \%$ were staying in various cyclone shelters at the time of this survey (as their homesteads had been inundated after an embankment breach during cyclone Amphan). These respondents were inclined to return to their homes once the inundation subsided. Therefore, in line with the definition mentioned in the "Analytical approach" sub-section, we would consider the sample respondents who willingly did not migrate as voluntary nonmigrant and the others would be considered as involuntary non-migrant in this study.

Table 1 presents the mean comparison between voluntary and involuntary non-migrants on several issues. Interestingly, for most of the issues, no significant and systematic difference was found between voluntary and involuntary non-migrants of this study. It implies both of the aforesaid groups appeared to live in similar situation and/or context in terms of literacy, household size, income, hazard exposure, land loss due to river erosion, pressure from social elites and political leaders, and degree of access to natural resources. Though there were only a few issues (i.e., four out of 17) where concern results show a systematic and significant difference between voluntary and involuntary non-migrants, interestingly, one result suggests that the mean number of religious conflicts was found different than zero for the aforesaid groups and this result is statistically significant. We would verify this result later in this paper.

\section{Quantitative strategies deployed for analysis}

We performed a principal component analysis (PCA) followed by a logistic regression model to explore the principal components (i.e., major dimensions) and capture the influence of various factors (i.e., variables), respectively, on the voluntary non-migration decision. Furthermore, all variables used for this purpose were on a 5-point Likert scale (see Table A in Appendix), for which PCA has been identified as an appropriate technique (Field 2013) to capture the reduced number of dimensions explaining voluntary non-migration.

Table 2 presents the results of the PCA, where we extracted four principal components with an eigenvalue of at least 1.5 , which altogether explained nearly $54 \%$ of the total variation. The Kaiser-Meyer-Olkin (KMO) measure denoted slightly over $78 \%$ accuracy for sampling adequacy while the Bartlett's test of sphericity was also statistically significant $\left(\chi^{2}(231)=5083.912, p<0.000\right)$ implying that the correlation matrix is not an identity matrix. Cronbach's alpha for this PCA was found $76.4 \%$ which is good enough. The average communality was estimated as 0.54 , which is ideal considering the sample size of our study. We applied the Oblimin rotation method with Kaiser normalization in this PCA which specified more interpretable factors. Factor loadings above 0.4 were considered and reported for PCA.

After performing the PCA, we deployed a binary logistic regression model to estimate the likelihood of the 
Table.1 Mean difference between voluntary and involuntary non-migrants on different issues

\begin{tabular}{llll}
\hline Variables & $\begin{array}{l}\text { Voluntary } \\
\text { non-migrant } \\
(N=490)\end{array}$ & $\begin{array}{l}\text { Involuntary non- } \\
\text { migrant }(N=66)\end{array}$ & $\begin{array}{l}\text { Test-statistic }(p \text { value }) \\
\text { [effect size }]^{*}\end{array}$ \\
\hline Schooling years & 5.098 & 5.030 & $0.122(p<0.910)[0.02]$ \\
Household size & 4.745 & 5.197 & $1.531(p<0.130)[0.20]$ \\
Number of physically challenged members & 0.131 & 0.303 & $3.35(p<0.001)[0.44]$ \\
$\quad$ in household & & & $1.033(p<0.302)[0.14]$ \\
Number of earning member in household & 1.304 & 1.394 & $1.282(p<0.201)[0.02]$ \\
Monthly income & 2560 & 3511 & $2.7(p<0.007)[0.35]$ \\
Monthly consumption expenditure & 10,000 & 13,000 & $0.86(p<0.390)[0.11]$ \\
Number of poultry & 3.612 & 4.197 & $1.68(p<0.094)[0.22]$ \\
Number of cattle & 1.337 & 0.833 & $1.194(p<0.233)[0.16]$ \\
Distance to river & 0.387 & 0.461 & $0.339(p<0.734)[0.04]$ \\
Land lost due to river erosion & 0.908 & 0.970 & $3.622(p<0.000)[0.47]$ \\
Religious conflict & 0.0860 & 0.318 & $0.545(p<0.596)[0.07]$ \\
Political threat & 1.778 & 1.591 & $0.375(p<0.708)[0.05]$ \\
Number of interactions with political leader & 0.735 & 0.682 & $2.77(p<0.006)[0.36]$ \\
Number of interactions with social elites & 0.982 & 0.530 & $0.577(p<0.5650$ [0.08] \\
Number of feeling marginalized & 1.202 & 1.106 & $0.094(p<0.925)[0.01]$ \\
Generations living here & 2.510 & 2.500 & $1.324(p<0.186)[0.17]$ \\
Time required to reach cyclone shelter & 26.03 & 22.68 & \\
\hline This denos & &
\end{tabular}

*This denotes the power of repetitive measures design. In this case, we divided the whole sample into two groups (voluntary and involuntary non-migrants), where "systematically" refers to the effect size (i.e., power) of the repetitive measure, which is demonstrated by Point-Biserial $(r)$. For a detailed explanation, see Field (2013) determinants affecting the voluntary non-migration decision of the respondents. Table 3 presents results of the regression model, where we considered the dependent variable's value as 1 if the respondent is a voluntary non-migrant and 0 otherwise (i.e., if he/she is an involuntary non-migrant). Along with the independent variables presented in Table 3, we also plugged-in predicted values of four components of PCA as independent variables. We report odd ratios for this regression model in Table 3.

\section{Major dimensions of voluntary non-migration decision}

\section{Dynamic social issues}

Mutual discussions during face-to-face household survey and FGDs unveiled the critical issues affecting the voluntary non-migration decision of the respondents in the study locations. Based on the absolute values of factor loadings presented in Table 2, the first principal component explaining almost $25 \%$ of the total variation represents the features of socioeconomic and sociopsychological advantages. These advantages were reflected through variables such as decision-making power, affordable living cost, place attachment perception, sense of security, better income prosperity, better social capital, financial help after a disaster, a safety net advantage in future, skill to stay at current location, easy access to safe drinking water, cyclone shelter, and local market. These findings are reflected by the place attachment (box 7), social capital (box 8), and economic opportunities (box 4) dimensions presented in our customized theoretical framework in Fig. 1. Concern result from logistic regression model (Table 3 ) suggests that the voluntary non-migrants appeared to enjoy 2.15 times higher socioeconomic and sociopsychological advantage (i.e., first principal component) than that of involuntary non-migrants in the study locations. The following statement of a FGD female participant from a religious minority group would help us visualizing the situation.

“....After cyclone Sidr in 2007, this area was inundated for almost two years. After cyclone Aila hit in 2009, we were inundated again for another three years. We had no hope for living here. Despite facing such hazard risks, we still live here because the environment of the society in this area is very much favorable for me. In our nearby river, there is presence of high and low tide. At the time of low tide, the inundation does not last for around six hours when we can perform our necessary activities. Moreover, the mangrove forest Sundarbans provides us huge support for living. 
Table.2 Principal component analysis (PCA) results showing major dimensions of non-migration decision

\begin{tabular}{|c|c|c|c|c|c|c|}
\hline \multirow[t]{2}{*}{ Variables } & \multirow[t]{2}{*}{ Communalities } & \multicolumn{4}{|c|}{ Components } & \multirow{2}{*}{ Major dimensions } \\
\hline & & 1 & 2 & 3 & 4 & \\
\hline Never wanted to leave this place & .543 & .654 & & & & Socioeconomic and \\
\hline Specific skill to stay at current location & .624 & .755 & & & & sociopsychological \\
\hline Decision-making power in society & .427 & .641 & & & & \\
\hline Felt secured & .625 & .701 & & & & \\
\hline Affordable living cost & .624 & .755 & & & & \\
\hline Better social capital & .473 & .478 & & & & \\
\hline Better income prospect & .572 & .571 & & & & \\
\hline Financial assistance in post-disaster time & .516 & .555 & & & & \\
\hline Future advantage of safety net program & .474 & 672 & & & & \\
\hline Access to safe drinking water & .467 & .692 & & & & \\
\hline Easy access to cyclone shelter & .360 & .558 & & & & \\
\hline Easy access to local market & .510 & .539 & & .452 & & \\
\hline Help from political leader & .580 & & .737 & & & Local support/advantages \\
\hline Help from social elites & .589 & & .705 & & & \\
\hline Government support in emergency & .437 & & .675 & & & \\
\hline Non-government support in emergency & .372 & & .540 & & & \\
\hline Access to natural resource for food collection & .573 & & & .738 & & Natural resource support \\
\hline Access to natural resource for fuel & .564 & & & .697 & & \\
\hline Access to natural resource for farming & 601 & & & .711 & & \\
\hline Access to natural resource for livestock rearing & .519 & & & 675 & & \\
\hline Cyclone risk exposure & .565 & & & & .646 & Disaster risk perception \\
\hline Flood risk exposure & .732 & & & & .854 & \\
\hline River bank erosion exposure & .743 & & & & .861 & \\
\hline
\end{tabular}

- Extraction method: principal component analysis

- Rotation method: Oblimin with Kaiser normalization

- Rotation converged in 10 iterations

Here, around $80 \%$ people depend on the forest by collecting fish, crab, wax, wood, and honey. There is no reason for migrating except river-bank erosion. None migrated from here for political reasons. Here, people of different religions live together in social harmony and brotherhood. Social tie is an important reason for not migrating from this area. Our government and other agencies are committed to reconstruct the damaged embankment. We expect that this area will be developed in the future. I possess an amicable social acceptance here, and if I migrate, I possibly cannot attain this acceptance in a new place."

\section{Local advantages}

The second principal component, explaining slightly over $11 \%$ of the total variation, depicts the local advantages during both disaster and normal times, which is reflected through variables such as help from social elites and political leaders as well as government and non-government supports. These issues are exhibited through location-specific advantages (box 8) in the customized framework in Fig. 1. Concern regression result in Table 3 suggests that these voluntary non-migrants were less likely to avail $62 \%$ local support from different government and non-government organizations (i.e., second principal component) compared to involuntary non-migrants. Furthermore, results denote that voluntary non-migrants inclined to have 3.7 times higher connection with local social elites than their counter group.

\section{Access to natural resources}

The third principal component implies the factors related to availing the advantage of accessing to diverse natural resources for food and livelihood diversification purposes, which are translated into variables such as food collection, fuel collection, farming, and livestock rearing. This component explains nearly $11 \%$ of the total variation and these are reflected through economic activities and opportunities in the theoretical framework (box 5) in Fig. 1. Regression result for the third principal component (in Table 3), however, denotes that voluntary non-migrants seemed to enjoy just 
Table.3 Logistic regression results

\begin{tabular}{|c|c|}
\hline Explanatory variables & Odds ratio $(\mathrm{SE})$ \\
\hline Socioeconomic and sociopsychological advantage (first principal component) & $2.150 * * *(0.497)$ \\
\hline Local support/advantages (second principal component) & $0.381 * * *(0.0954)$ \\
\hline Natural resource support (third principal component) & $1.358(0.266)$ \\
\hline Disaster risk perception (forth principal component) & $1.312(0.303)$ \\
\hline Male household head (interaction term) & $3.243 * * *(1.356)$ \\
\hline Per capita annual consumption expenditure (in US\$) & $0.999(0.000884)$ \\
\hline Age & $0.969 *(0.0182)$ \\
\hline Schooling years & $1.031(0.0541)$ \\
\hline Household size & $0.783 * * *(0.0642)$ \\
\hline Number of physically challenged members in household & $0.141 * * *(0.0517)$ \\
\hline Land lost due to river erosion & $1.001(0.148)$ \\
\hline Waterlogged days*presence of embankment (interaction term) & $1.033 * * *(0.0122)$ \\
\hline Employment status & $0.968(0.0407)$ \\
\hline Religious conflict & $0.722(0.183)$ \\
\hline Political threat & $1.026(0.0856)$ \\
\hline Interactions with political leader & $0.722(0.149)$ \\
\hline Interactions with social elites & $3.700 * * *(1.117)$ \\
\hline Living duration & $1.063 * * *(0.0178)$ \\
\hline Accessed natural resource sources & $0.944(0.154)$ \\
\hline Government emergency support & $0.986(0.116)$ \\
\hline Non-government emergency support & $1.124(0.194)$ \\
\hline Constant & $5.171(5.930)$ \\
\hline Observations & 556 \\
\hline $\operatorname{LR~chi}^{2}(21)$ & $202.80(p<0.000)$ \\
\hline Pseudo- $R^{2}$ & 50.06 \\
\hline Model correctly classified & $93.35 \%$ \\
\hline AIC & 246.347 \\
\hline BIC & 341.4039 \\
\hline
\end{tabular}

Standard errors in parentheses

${ }^{* * * *} p<0.01, * * p<0.05, * p<0.1$ over 35\% more advantage from different natural resources than that of their counter group though the result is not statistically significant.

\section{Disaster risk perception}

Explaining slightly over 7\% of the total variation, the fourth principal component portrays the disaster risk perceptions of the respondents (reflected in box 12 of customized theoretical framework in Fig. 1), which are illustrated through variables such as the risk exposures of the cyclone, flood, and river bank erosion. Though not statistically significant, the concern regression result in Table 3 suggests that voluntary non-migrants appeared to possess disaster risk perception by $31 \%$ more than their counterpart group. Diverse features captured by the four principal components can be further justified via the following statement by a household respondent from a local indigenous community (known as Munda) during survey.
"More than 380 households are living in my locality at present. In the aftermath cyclone Aila, nearly 15 households migrated from my community while some new households came in and settled down here. Some households left this place as the salinity intrusion affected their agricultural and fish farming after cyclone Aila. Despite livelihood challenges, we do not have any social unrest in our area even in the presence of people from different religions and political ideologies. People in my locality share their challenges and happiness with each other. We participate in the program of other religion to keep our brotherhood strong. In my lifetime, I have never seen any religious conflict in my community though sometimes there are visible impacts in our community due to religious contradictory views from national level.

Despite the presence of so many problems, people still live here because of the support of Sundarbans, fishing opportunities, known place, relatives, and finan- 
cial constraints. The old-aged people are less eager to migrate than younger people as they do not want to migrate at their old-age. They think that they will not live much longer, and that they should live and die in their own motherland. But young generations are ready to leave if they get better opportunities."

\section{Other issues}

Here we report some of the empirical findings based on the regression model presented in Table 3. Though the variable age exhibits that the odds of voluntary non-migrants as being 3\% less likely than their counter part, concerned chi-squared test result implies that non-migration decision does not have any association with age groups ${ }^{5}$ $\left(\chi^{2}(4)=4.7548, p<0.313\right)$. Again, the odd of voluntary non-migrant is 3.2 times higher than their counter group in case the household was male headed. Furthermore, we did not find any significant result for female respondents in case of interaction with political leaders $(z=0.34, p<0.732)$, local social elites $(z=1.43, p<0.154)$, access to government's $(z=0.359, p<0.719)$, and non-government organizations' $(z=0.128, p<0.898)$ emergency support. Results suggest that larger households were 0.22 times less likely to be voluntary non-migrants, and respondents living near embankment who suffered longer periods of waterlogging were three times more likely to be voluntary non-migrants compared to their counter group. Thus, gender and intrahousehold structures seemed to be important in case of choice of immobility decision. Considering the living span, result implies that the respondents living in the same/adjacent locality for longer time appeared to be nearly six times greater odd to be voluntary non-migrants. Again, interaction with social elites inclined to increase the odd of voluntary non-migration by 3.7 times. We found nearly $8 \%$ of our sampled respondents who were staying in their local cyclone shelter due to cyclone Amphan triggered inundation and they intended to return their homesteads once the inundation would over. Furthermore, we found only $2.7 \%$ of the respondents temporarily moved to elsewhere in a year for additional income, and we did not find any significant association between the said attempt and non-migration decision $\left(\chi^{2}(1)=0.974, p<0.324\right)$. Therefore, in this study, we did not find any evidence that trans-local issue affected the nonmigration decision.

\footnotetext{
${ }^{5}$ For this test, we categorized age into five groups: equal and less than 20 years, $21-30$ years, $31-50$ years, $51-65$ years, and 65 years above.
}

\section{Dimensions behind involuntary non-migration}

We also attempted to explore the factors that inhibited people from relocating themselves (i.e., involuntary non-migrants). Empirical results suggest that these involuntary nonmigrants appeared to receive a significantly lower degree of assistance from their peer-groups $(z=1.87, p<0.062)$ during the post-emergency time. Furthermore, they lacked peer networks in other prospective areas where they could have migrated $\left(\chi^{2}(4)=26.49, p<0.000\right)$, had insufficient access to job-related information in other areas $\left(\chi^{2}(4)=22.47, p<0.000\right)$, volatile psychological condition to move elsewhere $\left(\chi^{2}(4)=47.31, p<0.000\right)$, and they thought that moving to other areas would be too costly for them to afford $\left(\chi^{2}(4)=15.97, p<0.00\right.$.). Furthermore, in case of having physically challenged member(s) in households, the odds of being involuntary non-migrant was nearly $86 \%$ higher than that of voluntary non-migrants (Table 3 ). A plausible reason, in this case, might be the additional cost (e.g., medical treatment) for such member would create a burden for the household head in case of migrating elsewhere.

\section{Discussion}

To address the complex non-migration phenomenon in a quantitative manner, we selected respondents living in our two study locations for at least 20 years, and the average living duration of our respondents in their localities was found to be nearly 42 years. Therefore, considering the living duration, in this study, our selected sample respondents appeared to be appropriate for investigating environmental non-migration behavior. Our empirical results suggest that respondents from all walks of life appeared to live in similar situations in the study locations (see Table 1 and Table B in Appendix), implying they suffered similar covariate climatic shocks almost every year causing significant economic and non-economic damages. Nevertheless, most of our sampled respondents (88\%) showed little interest to migrate from their current locations, whom we considered as voluntary non-migrants in this study. We summarize the discussion on heterogenous factors affecting voluntary non-migration decision under the following major dimensions.

\section{Societal and hazard exposure aspects}

Our empirical results on sociodemographic features suggest that gender and intra-household structures have been important to the choice of mobility decision which is consistent with our logistic regression result (see Table 3), 
and this finding is consistent with the study by Tebboth et al. (2019). Considering the hazard and exposure issues, empirical results suggest that voluntary non-migration decision exhibits statistical significant association with degree of cyclone risk exposure $\left(\chi^{2}(4)=25.55 ; p<0.000\right)$, salinity intrusion $\left(\chi^{2}(4)=29.18 ; p<0.000\right)$, waterlogging $\left(\chi^{2}(4)=19.51 ; p<0.001\right)$, and river bank erosion $\left(\chi^{2}(4)=19.86 ; p<0.001\right)$. This is supported by the statements from respondents (mentioned in the "Hazard damage scenario in study locations" section) that they accepted these climatic extreme events as usual incidents of their lives as they have been living with the climatic risks and exposure for most of their lifetime. Considering the said scenario, in this study, we further attempted to unveil the underlying motivations of voluntary non-migration, where concerned results imply that in the aftermath of climatic shocks (i.e., disasters), especially cyclones, the voluntary non-migrants appeared to receive support (cash and materials) from the government $\left(\chi^{2}(4)=49.97 ; p<0.000\right)$, food and non-financial logistic support from relatives and peer groups $\left(\chi^{2}(4)=30.18 ; p<0.000\right)$, emergency relief and rehabilitation support from local political leaders $\left(\chi^{2}(4)=49.22 ; p<0.000\right)$, and financial support from other sources (e.g., local social elites) $\left(\chi^{2}(4)=9.26 ; p<0.05\right)$. These results denote such receiving of financial and nonfinancial supports and expectations from the community appeared to motivate these people at risk to become voluntary non-migrants. These findings are consistent with findings of the studies by Tebboth et al. (2019), Zickgraf (2019), Fischer et al. (2000), and Schewel (2020).

\section{Community-level support and access to natural resources aspects}

Results suggest that respondents' monthly consumption was nearly four times higher than their income (see Table B in Appendix), where the voluntary non-migrants had lower levels of both monthly income and consumption than those of involuntary non-migrants (see Table 1). Again, among voluntary non-migrants, approximately $89 \%$ reported to be employed though just over $90 \%$ of them claimed not to have a regular monthly income. Under the circumstances, a valid question would be as follows - how these voluntary non-migrants managed their additional funds to maintain their required consumption expenditure, as their said expenditure was found to be higher than their income (Table 1). Result suggests these voluntary non-migrants received required supports from relatives and peer network $\left(\chi^{2}(1)=34.20 ; p<0.000\right)$ and formal-informal connections in community $\left(\chi^{2}(1)=6.66 ; p<0.01\right)$ implying a substantial level of mutual assistance and cooperation for the respondents at the community level, which helped them to smoothen their consumptions. These empirical findings reasonably agree with conclusions of previous studies by Hjälm (2014), Schewel (2020), Black et al. (2013), and Ayeb-Karlsson et al. (2019). Again, these voluntary non-migrants appeared to avail significant advantages of accessing to natural resources for their food $\left(\chi^{2}(4)=14.38 ; p<0.01\right)$, fuel collection $\left(\chi^{2}(4)=12.64 ; p<0.01\right)$, timber collection from nearby mangrove forest the Sundarbans $\left(\chi^{2}(4)=15.51 ; p<0.004\right)$, and fishing purpose $\left(\chi^{2}(4)=21.38 ; p<0.000\right)$. These findings are in line with the study findings by Bhusal and Kimengsi (2019), Schewel (2020), and Biswas and Mallick (2020).

\section{Social harmony and security in the communities}

The voluntary non-migrants appeared to feel secured in their localities $\left(\chi^{2}(4)=36.06 ; p<0.000\right)$, incur an affordable living cost $\left(\chi^{2}(4)=35.87 ; p<0.000\right)$, and expect better income prospects $\left(\chi^{2}(4)=19.92 ; p<0.001\right)$. In addition, they seemed to have greater participation in decision-making process in society $\left(\chi^{2}(4)=55.47 ; p<0.000\right)$, avail better social capital $\left(\chi^{2}(4)=57.80 ; p<0.000\right)$ along with availing of better prospect of social safety-net program $\left(\chi^{2}(4)=40.31 ; p<0.000\right)$. All these results are reflected in the first component in principal component analysis (Table 2). These results are consistent with study findings by Yonay et al. (2015), Amin (2019), Zickgraf (2019), and Mallick and Schanze (2020). Concern results also imply a harmonic and congenial living condition with cultural affinity in our study locations as no substantial political and religious conflicts, threats, and marginalization attempts were reported. These facts are also consistent with study findings by Bell et al. (2021), Yonay et al. (2015), and Schewel (2020).

\section{Social network and mutual support among the community members}

These voluntary non-migrants appeared to develop a kind of social capital over time in their localities by maintaining a relationship with different local groups such as political leaders, social elites, peer groups, relatives, NGO people, and other formal agencies (e.g., local government). These relationships helped them to cope with the adverse impacts of climatic shocks. Furthermore, the favorable degree of access to different local natural resources (e.g., forest, fishery) helped them to ensure food and livelihood support. In summary, place attachment, social ties among the people, and social and political harmony appeared to strengthen the community's resilience capacity and positively influence their decision to become voluntary non-migrants. Some of the current voluntary non-migrants might have previously been involuntary non-migrants, but over time they adapted to the aforesaid local endowments and decided not to leave. 
The following statement from a FGD participant helps us to visualize the scenario that voluntary and involuntary nonmigration is not absolute, considering aspiration and capacity nexus.

"(with a deep breath).....I have been facing numerous challenges throughout my lifetime to live in this locality. Almost every year cyclone and river-bank erosion cause significant sufferings for us by creating volatile income. There are many people who lost either their lands or houses due to river-erosion over the last several decades. I lost my little piece of land after cyclone Aila. Usually, I work as a contract labor in my locality, especially during the harvesting period. But after recent cyclone Amphan- I do not have regular income opportunity and currently, other livelihood options are nearly unavailable for me. Nevertheless, I live here and still want to live here because this is my own and my forefathers' birthplace and I receive support from my relatives, friends, local social elites, and periodical schemes from the government. Even being poor in the community - I neither faced any threat or pressure from any political person nor marginalization-attempts by local social elites in my lifetime so far. I am quite happy with the social cohesion here even though my income is not always consistent. Years back I thought about moving to elsewhere for better livelihood, but now I don't want to move due to aforesaid reasons. I know a couple of persons who also wanted to go elsewhere but finally decided to stay here for the same reasons."

In summary, our empirical results suggest that both the voluntary and involuntary environmental non-migrants in our study locations live in a similar situation in terms of exposure to different climatic extreme events (e.g., cyclones, flood). Nevertheless, just over $88 \%$ of respondents have reported themselves as voluntary non-migrants who received financial (cash) and non-financial (i.e., food and materials) support from the community to help overcome the difficulties in post-hazard situations. These non-migrants seemed to be involuntary (i.e., trapped) non-migrants at an earlier stage of their lifetime. Over time, however, they became voluntary non-migrants. Our results did not find any role of trans-local issues for these voluntary non-migrants, implying a disagreement with the study findings by Rockenbauch et al. (2019) and Mallick and Schanze (2020). This same group of non-migrants has smoothened their consumption by receiving support from the community, friends, and peer groups in case of their volatile income. Our results suggest that these voluntary non-migrants felt secured in their localities, as they have not encountered any significant degree of political or religious conflict including threats from social pressure groups. Furthermore, this same group has enjoyed significant advantages of access to different local natural resources (e.g., forest, fishery) to support their livelihoods. This combination of social and livelihood security, along with the development of strong ties (i.e., social capital) in the community, led to a favorable environment that motivated the voluntary non-migrants to remain at their current places despite facing significant climatic risks and shocks. On the flip side, for the involuntary non-migrants, the decision to migrate appeared to be extremely difficult and costly due to their weak peer network and financial insolvency as suggested by our empirical findings.

\section{Concluding remarks}

This study has attempted to contribute to the existing (im) mobility-related literature from the lens of social science, by unveiling the factors motivating households at risk to become voluntary non-migrants in the hazard-prone coastal Bangladesh. Applying a mixed method, our empirical findings denote that even in the face of hazard events, people at risk's degree of non-migration behavior in coastal Bangladesh appeared to be high for a relatively lengthy period, with social capital, social harmony, mutual support, and access to natural resources playing pivotal roles behind the non-migration behavior. Thus, our empirical findings refute the traditional notion of economic opportunities motivating migration decisions (Martin et al. 2017), together with the findings of Penning-Rowsell et al. (2013) suggesting shortterm migration following hazard shocks in Bangladesh.

To the best of the knowledge of the authors, this is the first study to have applied mixed methods to empirically investigate the determinants affecting voluntary environmental non-migration decisions in coastal localities of Bangladesh. Unlike the previous handful of studies addressing non-migration issue from the perspective of either socioecological or sociopolitical or livelihood diversification or behavioral dimensions, our current study incorporated the socioeconomic, sociopsychological, and sociopolitical aspects to assess the said issue. However, this current study did not consider role of remittance, seasonal migration, trans-local aspects, and household's split (i.e., majority of household staying while few members migrate to other towns) within the scope of assessing migration decision. Furthermore, due to the operational definition, this study considers the non-migration decision only from an absolute perspective (i.e., binary), though the said decision might be relative in some cases along with a new sample selection method. Therefore, future studies may take these issues into consideration to conduct a more comprehensive story.

Supplementary Information The online version contains supplementary material available at https://doi.org/10.1007/s10113-021-01864-1. 
Acknowledgements We are particularly grateful for support provided by the students from different universities of Bangladesh during data collection. We would like to thank all the reviewers, series editor, and editor for their valuable comments and suggestions to improve this paper. The usual disclaimer applies.

Funding This study is funded by the Asia-Pacific Network for Global Change (APN) under Collaborative Regional Research Programme (CRRP) with project reference number CRRP2019-01MY-Kumar.

Open Access This article is licensed under a Creative Commons Attribution 4.0 International License, which permits use, sharing, adaptation, distribution and reproduction in any medium or format, as long as you give appropriate credit to the original author(s) and the source, provide a link to the Creative Commons licence, and indicate if changes were made. The images or other third party material in this article are included in the article's Creative Commons licence, unless indicated otherwise in a credit line to the material. If material is not included in the article's Creative Commons licence and your intended use is not permitted by statutory regulation or exceeds the permitted use, you will need to obtain permission directly from the copyright holder. To view a copy of this licence, visit http://creativecommons.org/licenses/by/4.0/.

\section{References}

Adams H (2016) Why populations persist: mobility, place attachment and climate change. Popul Environ 37:429-448. https://doi.org/ 10.1007/s11111-015-0246-3

Adger WN, Pulhin JM, Barnett J, Dabelko GD, Hovelsrud GKM et al (2014) Human security. In: Field CB, Barros VR, Dokken DJ, Mach KJ, Mastrandrea MD, Bilir TE, Chatarjee M, Ebi KL, Estrada YO, Genova RC, Girma B, Kissel ES, Levy AN, MacCraken S, Mastrandrea PR, White LL (eds) Climate change 2014: impacts, adaptation, and vulnerability. Part A: Global and sectoral aspects. Contribution of Working Group II to the Fifth Assessment Report of IPCC. Cambridge University Press, Cambridge and New York 755-791

Ahsan MN, Khatun A (2020) Fostering disaster preparedness through community radio in cyclone-prone coastal Bangladesh. International Journal of Disaster Risk Reduction 49:101752. https://doi. org/10.1016/j.ijdrr.2020.101752

Ahsan MN, Khatun A, Islam MS, Vink K, Ohara M, Fakhruddin BSHM (2020) Preferences for improved early warning services among coastal communities at risk in cyclone prone south-west region of Bangladesh. Progress in Disaster Science 5:100065. https://doi.org/10.1016/j.pdisas.2020.100065

Ahsan MN, Takeuchi K, Vink K, Warner J (2016) Factors affecting the evacuation decisions of coastal households during Cyclone Aila in Bangladesh. Environ Hazards 15:16-42. https://doi.org/10.1080/ 17477891.2015.1114912

Amin C Modeling (Im) mobility: the decision to stay in disaster prone area amongs fishermen community in Semarang. In: E3S Web of Conferences, 2019. EDP Sciences 03012

Ayeb-Karlsson S, Kniveton D, Cannon T (2020) Trapped in the prison of the mind: notions of climate-induced (im)mobility decisionmaking and wellbeing from an urban informal settlement in Bangladesh. Palgrave Commun 6:62. https://doi.org/10.1057/ s41599-020-0443-2

Ayeb-Karlsson S, Kniveton D, Cannon T, van der Geest K, Ahmed IEM et al (2019) I will not go, I cannot go: cultural and social limitations of disaster preparedness in Asia, Africa, and Oceania. Disasters 43:752-770. https://doi.org/10.1111/disa.12404
Ayeb-Karlsson S, Smith CD, Kniveton D (2018) A discursive review of the textual use of 'trapped' in environmental migration studies: the conceptual birth and troubled teenage years of trapped populations. Ambio 47:557-573. https://doi.org/10.1007/ s13280-017-1007-6

Bal E, Willems R (2014) Introduction: Aspiring migrants, local crises and the imagination of futures 'away from home.' Identities 21:249-258. https://doi.org/10.1080/1070289X.2014.858628

BBS (2016) Household Income and Expenditure Survey (HIES) 20052016. http://bbs.portal.gov.bd/sites/default/files/files/bbs.portal. gov.bd/page/b343a8b4_956b_45ca_872f_4cf9b2f1a6e0/Compa rative\%20Matrix\%20HIES_fnl.pdf. Accessed 01 Aug 2019

Bell AR, Wrathall DJ, Mueller V, Chen J, Oppenheimer M et al (2021) Migration towards Bangladesh coastlines projected to increase with sea-level rise through 2100. Environ Res Lett 16:024045. https://doi.org/10.1088/1748-9326/abdc5b

Bhusal P, Kimengsi JN (2019) What drives environmental (non) migration around the Himalayan Region? Evidence from Rural Nepal. Paper presented at the Environmental Non-migration: Frameworks, Methods and Cases, Technische Universitat Dresden, July 29

Biswas B, Mallick B (2020) Livelihood diversification as key to longterm non-migration: evidence from coastal Bangladesh. Environ Dev Sustain. https://doi.org/10.1007/s10668-020-01005-4

Biswas JC, Maniruzzaman M, Haque M, Hossain M, Rahman et al (2018) Extreme climate events and fish production in Bangladesh. Environment and Natural Resources Research 9(01):10.5539. https://doi.org/10.5539/enrr.v9n1p1

Black R, Arnell NW, Adger WN, Thomas D, Geddes A (2013) Migration, immobility and displacement outcomes following extreme events. Environ Sci Policy 27:S32-S43. https://doi.org/ 10.1016/j.envsci.2012.09.001

Comprehensive Disaster Management Programme-II (2014) Trend and impact analysis of internal displacement due to the impacts of disaster and climate change. Ministry of Disaster Management and Relief, Dhaka. https://reliefweb.int/sites/reliefweb. int/files/resources/CDMP-Internal-Displacement-BangladeshAnalysis.pdf. Accessed 03 Dec 2020

Carling J, Collins F (2018) Aspiration, desire and drivers of migration. J Ethn Migr Stud 44:909-926. https://doi.org/10.1080/ 1369183X.2017.1384134

EM-DAT (2020) Damages due to hydro-meteorological hazards in Bangladesh. http://emdat.be/dbase. Accessed 27 Oct 2020

Field A (2013) Discovering statistics using IBM SPSS statistics, 4th edn. Sage Publications Ltd., London

Fischer PA, Holm E, Malmberg G, Straubhaar T (2000) Why do people stay? Insider advantages and immobility. HWWA Discussion Paper 112. https://www.econstor.eu/handle/10419/19439. Accessed 21 Nov 2020

HDX (2020) Bangladesh - Subnational Administrative Boundaries. The Humanitarian Data Exchange. https://data.humdata.org/ dataset/administrative-boundaries-of-bangladesh-as-of-2015. Accessed 18 Nov 2020

Hjälm A (2014) The 'stayers': dynamics of lifelong sedentary behaviour in an urban context. Popul Space Place 20:569-580. https:// doi.org/10.1002/psp.1796

Hunter LM, Luna JK, Norton RM (2015) Environmental dimensions of migration. Ann Rev Sociol 41:377-397. https://doi.org/10. 1146/annurev-soc-073014-112223

Hunter LM (2005) Migration and environmental hazards. Popul Environ 26:273-302. https://doi.org/10.1007/s11111-005-3343-x

IDMC (2020) Global Report on Internal Displacement. Internal Displacement Monitoring Centre. https://www.internal-displaceme nt.org/global-report/grid2020/. Accessed 11 Aug 2020

Jha CK, Gupta V, Chattopadhyay U, Sreeraman BA (2018) Migration as adaptation strategy to cope with climate change. 
Int J Clim Change Strateg Manag. https://doi.org/10.1108/ IJCCSM-03-2017-0059

Kumar P, Avtar R, Dasgupta R, Johnson BA, Mukherjee A et al (2020) Socio-hydrology: A key approach for adaptation to water scarcity and achieving human well-being in large riverine islands. Progress in Disaster Science 8:100134. https://doi.org/ 10.1016/j.pdisas.2020.100134

Mallick B (2019) The nexus between socio-ecological system, livelihood resilience, and migration decisions: empirical evidence from Bangladesh. Sustainability (Switzerland) 11. https://doi. org/10.3390/su 10023332

Mallick B, Schanze J (2020) Trapped or voluntary? Non-migration despite climate risks. Sustainability (Switzerland) 12https://doi. org/10.3390/su12114718

Mallick B, Sultana Z (2017) Livelihood after relocation-evidences of Guchchagram project in Bangladesh. Soc Sci 6https://doi.org/ 10.3390/socsci6030076

Mallick B, Sultana Z, Bennett CM (2020) How do sustainable livelihoods influence environmental (non-)migration aspirations? Appl Geogr 124:102328. https://doi.org/10.1016/j.apgeog.2020.102328

Martin M, Kang Yh, Billah M, Siddiqui T, Black R, Kniveton D (2017) Climate-influenced migration in Bangladesh: the need for a policy realignment. Dev Policy Rev 35:O357-O379. https://doi.org/10. $1111 /$ dpr. 12260

Olsson L, Opondo M, Tschakert P, Agrawal A, Eriksen SE (2014) Livelihoods and poverty. IPCC. https://www.ipcc.ch/site/assets/ uploads/2018/02/WGIIAR5-Chap13_FINAL.pdf. Accessed 14 May 2021

Penning-Rowsell EC, Sultana P, Thompson PM (2013) The 'last resort'? Population movement in response to climate-related hazards in Bangladesh. Environ Sci Policy 27:S44-S59. https://doi. org/10.1016/j.envsci.2012.03.009

Petrova K (2021) Natural hazards, internal migration and protests in Bangladesh. J Peace Res 58:33-49. https://doi.org/10.1177/00223 43320973741

Rockenbauch T, Sakdapolrak P, Sterly H (2019) Beyond the local exploring the socio-spatial patterns of translocal network capital and its role in household resilience in Northeast Thailand. Geoforum 107:154-167. https://doi.org/10.1016/j.geoforum.2019.09. 009

Schewel K (2020) Understanding immobility: moving beyond the mobility bias in migration studies. Int Migr Rev 54:328-355. https://doi.org/10.1177/0197918319831952

Shamsuddoha M, Khan SMMH, Raihan S, Hossain T (2011) Displacement and migration from climate hot-spots in Bangladesh: causes and consequence. Action Aid, Bangladesh. https://unfccc.int/files/ adaptation/groups_committees/loss_and_damage_executive_ committee/application/pdf/displacement_and_migration_from_ the_hot_spots_in_bangladesh_causes_and_consequences.pdf. Accessed 29 Aug 2020

Tebboth MGL, Conway D, Adger WN (2019) Mobility endowment and entitlements mediate resilience in rural livelihood systems. Glob Environ Chang 54:172-183. https://doi.org/10.1016/j.gloen vcha.2018.12.002

The UK Government Office for Science (2011) Foresight: migration and global environmental change. https://assets.publishing.servi ce.gov.uk/government/uploads/system/uploads/attachment_data/ file/287717/11-1116-migration-and-global-environmental-change. pdf. Accessed 01 Dec 2020

UNB (2020, 22 May) Cyclone Amphan: locals demand sustainable embankment. https://www.unb.com.bd/category/Bangladesh/ cyclone-amphan-locals-demand-sustainable-embankment/51961. Accessed 03 Dec 2020

van Heelsum A (2016) Why migration will continue: aspirations and capabilities of Syrians and Ethiopians with different educational backgrounds. Ethn Racial Stud 39:1301-1309. https://doi.org/10. 1080/01419870.2016.1159711

Vigil S, IOM, UNCCD (2019) Addressing the land degradation-migration nexus: the role of the United Nations Convention to Combat Desertification. Geneva: International Organization for Migration. https://environmentalmigration.iom.int/addressing-land-degra dation-/E2/80/93-migration-nexus-role-united-nations-conve ntion-combat-desertification. Accessed 14 May 2021

Yonay YP, Yaish M, Kraus V (2015) Religious heterogeneity and cultural diffusion: the impact of Christian neighbors on Muslim and Druze women's participation in the labor force in Israel. Sociology 49:660-678. https://doi.org/10.1177/0038038514547898

Zander KK, Garnett S (2020) Risk and experience drive the importance of natural hazards for peoples' mobility decisions. Clim Change 162:1639-1654. https://doi.org/10.1007/s10584-020-02846-8

Zickgraf C (2019) Keeping people in place: political factors of (im) mobility and climate change. Soc Sci 8https://doi.org/10.3390/ socsci 8080228

Publisher's note Springer Nature remains neutral with regard to jurisdictional claims in published maps and institutional affiliations. 